\title{
Isolated Gastric Tuberculosis: A Case Report and Review of Literature
}

\author{
Madhumita Mukhopadhyay • Quazi M. Rahaman • \\ Nisith R. Mallick • Dawood Khan • Sudipta Roy • \\ Niloy Biswas
}

Received: 18 November 2008 / Accepted: 3 December 2008/Published online: 16 November 2010

(C) Association of Surgeons of India 2010

\begin{abstract}
Isolated gastric tuberculosis is a rare condition, even in those parts of the world where intestinal tuberculosis is common. Herein we describe a case of a thirty year old female patient with isolated gastric tuberculosis who presented with features of gastric outlet obstruction.
\end{abstract}

Keywords Isolated gastric tuberculosis · Clinical features · Management

\section{Introduction}

Gastric tuberculosis whether as a primary or secondary infection is uncommon [1]. It is usually associated with pulmonary tuberculosis [2]. Isolated gastric tuberculosis without features of lesion elsewhere, is even rarer, with very few cases being reported in literature [3-7]. Lack of specific clinical, radiological and endoscopic features makes the diagnosis difficult [3]. We present a case of isolated gastric tuberculosis in a young female patient who presented with gastric outlet obstruction due to an ulcerated nodular mass in the antrum.

\section{Case Report}

A thirty year old female patient presented with complaints of nausea and vomiting for 5 months and epigastric pain for 4 months. She noticed a significant weight loss in the last

M. Mukhopadhyay $(\bowtie) \cdot$ Q. M. Rahaman $\cdot$ N. R. Mallick •

D. Khan $\cdot$ S. Roy $\cdot$ N. Biswas

Calcutta National Medical College \& Hospital,

Kolkata, India

e-mail: drmmeettuu@yahoo.co.in
2 months. Vomitus consisted of undigested food residue. Pain was precipitated by meals. There was no history of haematemesis, malena or any systemic illness. There was no past or family history of tuberculosis. The patient was non-diabetic. Her HIV status was negative. Clinical examination revealed epigastric fullness with succussion splash. Complete haemogram, renal and liver function tests and $\mathrm{x}$ ray chest were within normal limits. Mantoux test was negative. Upper GI endoscopy was suggestive of an ulcerated nodular mass at the antrum with a non-negotiable gastric outlet obstruction. Endoscopic mucosal biopsy did not reveal malignancy or granuloma. In view of gastric outlet obstruction without specific histological diagnosis, the patient was subjected to exploratory laparotomy.

On laparotomy the pylorus was stenosed and deformed. There was a large ulcero-nodular growth at the antrum. Distal gastrectomy was done with Roux - en - Y gastrojejunostomy (Fig. 1). Histopathology revealed granulomatus inflammation of tuberculous origin involving all the layers of the stomach and perigastric lymphnodes. Postoperative recovery was uneventful. The patient was put on antitubercular chemotherapy with a four drug regimen of isoniazide $300 \mathrm{mg}$, rifampicin $450 \mathrm{mg}$, ethambutol $900 \mathrm{mg}$ and pyrizinamide $1,500 \mathrm{mg}$ for initial 2 months followed by isoniazide and rifampicin in the same dose for another 4 months. On her first follow up visit, 1 month after discharge, she had gained $3 \mathrm{~kg}$ body weight and her appetite had improved.

\section{Discussion}

Gastric tuberculosis is a rare entity even in a country like India where tuberculosis is endemic. Usually gastric tuberculosis is secondary to pulmonary tuberculosis [2]. 


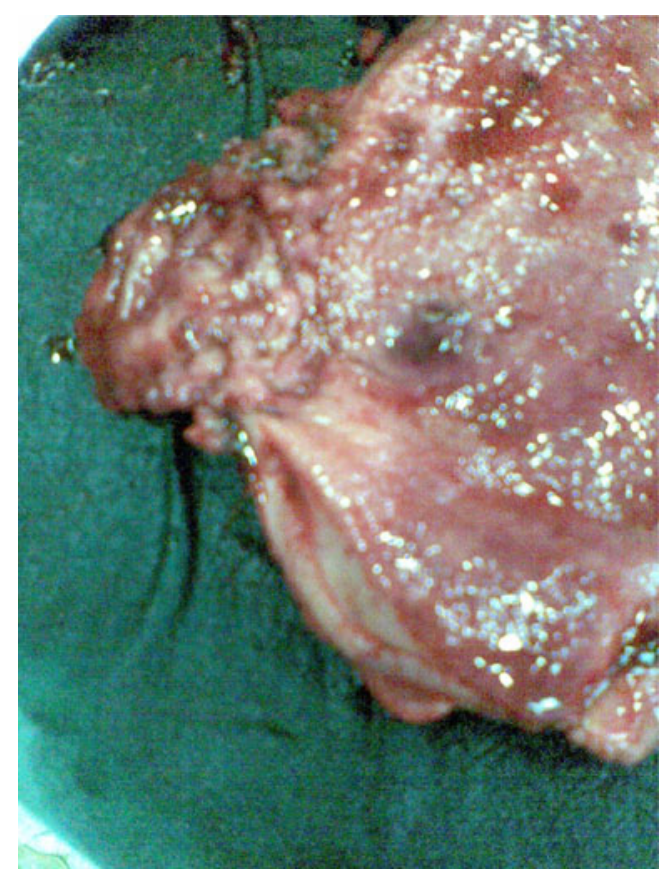

Fig. 1 Resected specimen of distal stomach showing ulcerated nodular mass

Isolated gastric tuberculosis without evidence of lesion elsewhere is even rarer [4]. The reason for this rarity is attributed to bactericidal property of gastric acid, scarcity of lymphoid tissue in the gastric wall and intact gastric mucosa of the stomach $[5,8]$. The possible routes of infection include direct infection of the mucosa, haematogenous spread or extension from a neighboring tuberculous lesion $[3,9]$.

The clinical presentation of gastric tuberculosis is entirely non-specific with complaints of epigastric pain, vomiting and weight loss $[4,10]$. Gastric outlet obstruction is the most common presentation of tuberculosis [6]. Other presentations reported in literature are haematemesis [11], perforation [1, 12], non healing ulcer [13], and dysphagia [5].

Endoscopic brush cytology and biopsy is only occasionally successful in diagnosis [10]. The diagnosis of tuberulosis requires demonstration of caseating epithelioid granuloma or presence of acid fast bacilli in tissue [5]. Antitubercular chemotherapy forms the mainstay of treatment when diagnosis of gastric tuberculosis is made. Due to lack of accurate clinical diagnosis and sensitive laboratory investigations, most patients need surgical intervention for diagnosis $[3,5]$. Even if diagnosed by endoscopic biopsy, surgery may be required for complications such as gastric outlet obstruction, perforation or bleeding.

\section{Conclusion}

Though rare, gastric tuberculosis should be kept in mind especially for patients presenting with gastric outlet obstruction in an endemic area. Antitubercular chemotherapy forms the mainstay of treatment. Surgery is required to relieve gastric outlet obstruction or for complications like haematemesis and perforation.

\section{References}

1. Palmer ED (1950) Tuberculosis of the stomach and the stomach in tuberculosis. Am Rev Tuberc 61:116-130

2. Brody JM, Miller DK, Zeman RK, Klappenbach RS, Jaffe MH, Clark LR, Benjamin SB, Choyke PL (1986) Gastric tuberculosis: a manifestations of acquired immunodeficiency syndrome. Radiology 159:347-348

3. Dargan P, Sinha SK, Singh N, Jain BK, Shrivastava UK (2005) Gastroduodenal tuberculosis: a report of three cases and review of literature. The Internet Journal of Gastroenterology 2(1)

4. Subei I, Attar B, Schmitt G, Levendoglu H (1987) Primary gastric tuberculosis: a case report and literature review. Am J Gastroenterol 82:769-772

5. Amarapurkar DN, Patel ND, Amarapurkar AD (2003) Primary gastric tuberculosis - a report of 5 cases. BMC Gastroenterol 3:6

6. Tromba JL, Inglese R, Rieders B, Todaro R (1991) Primary gastric tuberculosis presenting as pyloric outlet obstruction. Am J Gastroenterol 86:1820-1822

7. Salpeter SR, Shapiro RM, Gasman JD (1991) Gastric tuberculosis presenting as fever of unknown origin. West J Med 155:412-3

8. Lin OS, Wu SS, Yeh KT, Soon MS (1999) Isolated gastric tuberculosis of the cardia. J Gastroenterol Hepatol 14:258-61

9. Gupta B, Mathew S, Bhalla S (1990) Pyloric obstruction due to gastric tuberculosis: an endoscopic diagnosis. Postgrad Med J 60:62-65

10. Sharma BL, Prasad H, Bhasin DK, Singh K (2000) Gastroduodenal Tuberculosis presenting with massive hematemesis in a pregnant woman. J Clin Gastroenterol 30:336

11. Wig JD, Vaiphei K, Tashi M, Kochhar R (2000) Isolated gastric tuberculosis presenting as massive hematemesis report of a case. Surg Today 30:921-922

12. Clagett OT, Walters W (1938) Tuberculosis of the stomach. Arch Surg 37:505-20

13. Chetri K, Prasad KK, Jain M, Choudhuri G (2000) Gastric tuberculosis presenting as non-healing ulcer: case report. Trop Gastroenterol 21:180-181 